\title{
An assessment of critically ill children admitted to a general high-care unit in a regional hospital in Western Cape, South Africa
}

\author{
R Vosloo, ${ }^{1} \mathrm{MB}$ ChB, DCH (SA), FCPaed (SA); W J Breytenbach, ${ }^{2}$ MB ChB, FCPaed (SA); \\ S Salie, ${ }^{3}$ MB ChB, FCPaed (SA), Cert Crit Care (Paed), MPH \\ ${ }^{1}$ Department of Paediatrics and Child Health, Faculty of Health Sciences, University of Cape Town, South Africa \\ ${ }^{2}$ Department of Paediatrics and Child Health, George Regional Hospital, George, South Africa \\ ${ }^{3}$ Paediatric Intensive Care Unit, Red Cross War Memorial Children's Hospital and Department of Paediatrics and Child Health, University of \\ Cape Town, South Africa
}

Corresponding author: $R$ Vosloo (drruanvosloo@icloud.com)

\begin{abstract}
Background. Many critically ill children in South Africa (SA) are cared for by general paediatricians in regional hospitals. Limited data are available on the outcomes of these admissions.

Objective. To describe the profile and outcomes of children admitted to a general high-care unit (HCU) in a regional hospital in Western Cape, SA.

Methods. This was a retrospective descriptive study of all children admitted to the HCU of the George Regional Hospital during a 1-year period (2016). Demographic data, HIV status, anthropometric data, immunisation status, diagnoses, medical interventions, length of stay, outcome and referral data to the tertiary paediatric intensive care unit (PICU) were collected. The paediatric index of mortality 3 (PIM3) score and standardised mortality ratio (SMR) were calculated.

Results. Approximately a third $(n=144 / 468)$ of admissions were children. Most $(70 \%)$ were admitted after hours. Half were younger than 9 months (range 3 days - 149 months). Respiratory and inotropic support were needed in 65\% and $45 \%$ of the cases, respectively. A fifth of the children were transferred to the PICU. Twelve children (8.5\%) died, with most deaths $(n=9 / 12)$ occurring at regional level. The cumulative PIM3 score was 9.049 (95\% confidence interval (CI) 6.430 - 11.668), with the associated SMR calculated as 1.326 (95\% CI 1.028 - 1.866).

Conclusion. Critically ill children accounted for a third of HCU admissions, with most needing specialised medical intervention. Most children were successfully discharged, suggesting that a good outcome was possible owing to effective channels of communication and transport to a tertiary PICU.
\end{abstract}

S Afr J Child Health 2020;14(4):192-199. https://doi.org/10.7196/SAJCH.2020.v14i4.1706

Almost 34000 children under the age of 15 years died in South Africa (SA) in 2016, accounting for $7.4 \%$ of total deaths ( $n=34000 / 456$ 612). ${ }^{[1]}$ The number of deaths has been used to represent an estimate of people requiring critical care. ${ }^{[2]}$ Critical illness can be defined as illness or injury that acutely impairs one or more vital organ systems. This leads to a high risk of lifethreatening deterioration in the clinical condition, which requires critical care services. These are described as medical care delivered to a critically ill or injured person. ${ }^{[3]}$

Intensive care describes the highest level of patient monitoring and treatment and an intensive care unit (ICU) can be defined as a designated area where resources and equipment are concentrated to care for critically ill patients. The level of care and supervision is more sophisticated than in a general ward and ICUs can be subcategorised as: Category 1 - tertiary ICU facility; Category 2 - specialised organ support unit; Category 3 - high-care unit (HCU) ${ }^{[4]}$

Paediatric intensive care in the public sector is a limited resource. Most severely ill children in SA receive care from general paediatricians in mixed medical and surgical ICUs and HCUs that admit both adults and children. This is observed across both the public and the private sector. Of almost 4200 critical-care beds in SA, $\sim 20 \%(n=815 / 4168)$ are reserved for paediatric and neonatal patients in public and private hospitals. ${ }^{[5]}$ Approximately 1800 of the total number of critical-care beds are available in the government sector.

There are no clear guidelines on the number of ICU beds per population. Bed availability varies across the world and an increased number of ICU beds does not necessarily mean improved mortality. The SA ratio of 8.9 beds per 100000 people is comparable to that in Australia and Spain; however, the life expectancy in SA is only 54 years (compared with 82 years in Australia and Spain). The USA has up to 31.7 beds per 100000 people whereas Sri Lanka has only 1.6 per 100000 people, yet the life expectancy in these countries is similar. ${ }^{[6]}$

The SA under-5 mortality rate has decreased in recent years (estimated at $37-40 / 1000$ live births in 2015), with a substantial decrease - from 58.4/1 000 in 2008 to 31.1/1 000 live births in 2015 - seen in Western Cape Province. ${ }^{[7-9]}$ To reach Sustainable Development Goal 3 (SDG 3) by, among others, reducing the under- 5 mortality rate to 25 per 1000 live births by 2030 , more data on the profiles and outcomes of critically ill children in regional hospitals are needed. ${ }^{[10]}$ This includes all children needing high-dependency or intensive care, whether surgically, medically or trauma related. More data may reveal potential areas in which interventions could improve survival. ${ }^{[11]}$ 
George Regional Hospital serves both Eden and Central Karoo districts, with a joint population of $\sim 650000$ people ( $11 \%$ of the population in Western Cape) and of which almost 200000 are children under 15 years of age. ${ }^{[8,9]}$

Critically ill children have a higher mortality rate when cared for in mixed units; well-established models from developed countries show better outcomes in children when centralised paediatric critical care and retrieval services are available. ${ }^{[12,13]}$ However, data on the implementation of these models in low- or middleincome countries are lacking. ${ }^{[14]}$ In addition, the transport of critically ill children to a tertiary paediatric intensive care unit (PICU) also poses a challenge, with a high incidence of adverse transfer-related events shown in a recent study in Cape Town. ${ }^{[15]}$ Nevertheless, another study at Worcester Hospital, Western Cape, showed a good outcome in children admitted to a mixed HCU at a regional hospital. ${ }^{[16]}$

Other outcome modalities arising from paediatric critical care in the developed world are mortality prediction scores such as the Paediatric Index of Mortality (PIM) score, ${ }^{[17,18]}$ which is used as a tool to assess mortality risk. The standardised mortality ratio (SMR) can subsequently be calculated to provide a ratio of expected to observed deaths, which is used to compare care units. However, factors such as diagnostic profiles, medical and surgical cases, unit resources, protocols and so on also affect PIM scores. The SMR, therefore, compares more than quality of care ${ }^{[17]}$ The Paediatric Index of Mortality 2 (PIM2) model has been validated as an accurate comparative index of paediatric intensive care in many settings, including SA. ${ }^{[19-21]}$ In 2013, an updated Paediatric Index of Mortality 3 (PIM3) model was published. ${ }^{[22]}$ This model is currently being used and validated in PICUs across SA. However, in a recent study in KwaZulu-Natal Province, it has been shown to under-predict mortality. ${ }^{[23]}$ Although the PIM3 model has not been validated at the level of regional hospitals, the associated SMR could be used to compare the quality of care between different regional hospitals. ${ }^{[22]}$

\section{Methods \\ Setting and background}

The present study was conducted at George Regional Hospital's HCU. The unit has six critical-care bed spaces (Category 3), ${ }^{[4]}$ although none are reserved specifically for children. Patients are cared for by a staff of ten professional nurses, four staff nurses and two nursing assistants. During a shift, two or three professional nurses and one staff nurse or nursing assistant are on duty. Only one of the professional nurses is formally trained in paediatric critical care.

The management of medically and surgically ill children is overseen by the doctors of the respective specialty. The paediatric service consists of two general paediatricians, one subspecialist neonatologist, two senior medical officers and six junior doctors, including one registrar, three medical officers and two rotating medical interns. Together they serve the neonatal unit, general paediatric ward, HCU, outpatient department and emergency centre. They also provide outreach and referral services to the subdistricts.

In the surgical department there are four general surgeons, one general surgery registrar, five medical officers and two interns. There are no doctors allocated to working only in the HCU. After hours, admitted patients are the responsibility of one off-site consultant and one on-site junior doctor of each specialty (Surgery and Paediatrics). The after-hours team are also on call for the rest of the hospital.
There are four other higher-care beds available in the general paediatric ward and continuous positive airway pressure (CPAP) can be provided in the general ward. Generally, children are admitted to the HCU when intubation, inotropic support or more intensive monitoring is required. ${ }^{[4,24]}$ If patients require more than 72 hours of ventilation or if specific tertiary subspecialist critical care is required, patients are recommended for transfer to the designated tertiary PICU (Red Cross War Memorial Children's Hospital, Cape Town) via air ambulance. Admission to that PICU is determined by their admission criteria. $^{[24,25]}$

The neonatal intensive care unit (NICU) at George Regional Hospital provides care to ill neonates. The unit functions independently from the $\mathrm{HCU}$ and patients can be ventilated in the five-bed NICU. This unit is reserved for newborns who have not been discharged home from a healthcare facility prior to presentation.

\section{Study parameters and data collection}

The study analysed patient records for all children admitted to the HCU during 2016. Patient records were reviewed and in the case of transfer, the PICU database was consulted.

This study was performed to determine the profiles and outcomes of children admitted to the HCU. Data were collected for all paediatric admissions and included tertiary PICU stay outcome. Deaths were defined and limited to those occurring during the critical-care admission. Children were defined as younger than 13 years. Patient age, sex, immunisation status, HIV infection status, anthropometry (using the World Health Organization criteria and corrected for gestational age) and diagnoses were documented. ${ }^{[26]}$ Sepsis was defined as a culture-positive bloodstream infection with multi-organ dysfunction. Prematurity was defined as birth at a gestational age $<37$ weeks.

Other time-related data collected included time of admission to the hospital, time of HCU admission (after hours or during working hours), total duration of regional hospital admission, total duration of $\mathrm{HCU}$ admission, duration of critical care (including HCU, transfer and PICU stay), and transfer waiting period. Afterhours admission was defined as HCU admission after 17:00 and before 08:00 on weekdays, between 17:00 on a Friday and 08:00 on a Monday (weekends) and any public holiday. The reason for delay in PICU transfer, if more than 24 hours, was sought. Interventions in the form of respiratory support (CPAP or mechanical ventilation) and inotropic support were recorded and the duration of such interventions was noted. The PIM3 score was collected for all cases and the predicted mortality rate was compared with the actual mortality rate to calculate the SMR. ${ }^{[22]}$

\section{Data analysis}

The continuous variables were not normally distributed and data distribution is described according to medians and ranges. The $\chi^{2}$ test was used to analyse categorical variables. Continuous variables were compared with survival using the Kruskal-Wallis analysis of variance (ANOVA) test. Spearman correlation testing was performed to assess interobserver variability in PIM3 scoring.

\section{Ethical considerations}

Ethical approval was obtained from the Human Research Ethics Committee at the University of Cape Town (ref. no. 700/2016), along with a waiver of individual consent. Study approval was obtained from the Western Cape Department of Health and local hospital management. An informative poster was displayed outside the HCU to inform staff, patients and caregivers of the study. 


\section{Results}

Of the $468 \mathrm{HCU}$ admissions, 144 (30.77\%) were children. All 144 admissions were included in the study and all patient records were available (Fig. 1). Two children were re-admitted within 48 hours of discharge from the HCU; these were recorded as separate admissions. The male-to-female ratio was almost equal (Table 1). The median age and associated interquartile range (IQR) was $9(2-40)$ months. Three of the HIV-infected children were diagnosed at admission. Weight and height records were available in 134 and 114 cases, respectively. More than a third of cases $(37.32 \%$; $n=50 / 134)$ were underweight for their age (2 standard deviations (SD) or more below the $Z$-score), of whom $16.42 \%(n=22 / 134)$ were severely underweight $(Z<-3 \mathrm{SD})$. Stunting was also observed in a substantial proportion of patients (36.1\%; $n=39 / 108)$. As seen from the height-for-age data, a large number of these patients were severely stunted for age $(Z<-3$ SD) $(16.42 \%$; $n=24 / 108)$. Weight-forheight and body mass index data revealed that almost a quarter of subjects $(23.5 \%$, $n=25 / 108)$ were wasted $(Z<-2$ SD), with $10 \%$ $(n=11 / 108)$ being severely wasted $(Z<-3$ SD). Anthropometric values did not have an effect on survival. Eighteen admissions were born prematurely, including one of the deaths. Prematurity was not associated with a higher death rate $(p=0.510)$.

Twelve patients $(8.5 \% ; n=12 / 142)$ died during admission, of whom six were diagnosed with sepsis. Pneumonia $(n=3 / 12)$ and diarrhoea with shock $(n=3 / 12)$ were recorded in the remaining deaths. Half of the deaths occurred in children under 6 weeks of age (IQR 3 weeks - 28 months). Most deaths $(75 \% ; n=9 / 12)$ occurred in the HCU and within 4 days of admission. Three deaths occurred at tertiary level. The exact time of death was available for 11 of the deaths. The median time to death was 2 days (range 7 hours - 22 days).

The median duration of admission to George Regional Hospital was 6 days (range 8 hours - 77 days). The patients who died tended to be admitted for a shorter period prior to death or transfer to the PICU $(p=0.004)$. The median duration of HCU admission was 1 day and 17 hours (range 18 minutes - 13 days) (Table 2). The median time awaiting transfer to the PICU was 12 hours (range 3 hours - 12 days).

Table 3 shows the reasons for delay in PICU transfer. There were no mortalities during transfer and no association between transfer and death $(p=0.754)$. The median duration of PICU stay was 6 days (range 6 hours - 31 days). Data regarding duration of PICU stay were not available for 7 patients. No significant association was observed between duration of PICU stay and mortality $(p=0.306)$ in 29 PICU transfers.

Children who died all required respiratory or inotropic support, or both $(p=0.000)$. Table 4 summarises interventions received by the study population. The median duration for respiratory support (CPAP, intermittent positive pressure ventilation or both) was 4 days (range 3 hours - 33 days). The median duration of inotropic treatment was 2 days (range 3 hours - 14 days). These statistics include support provided at

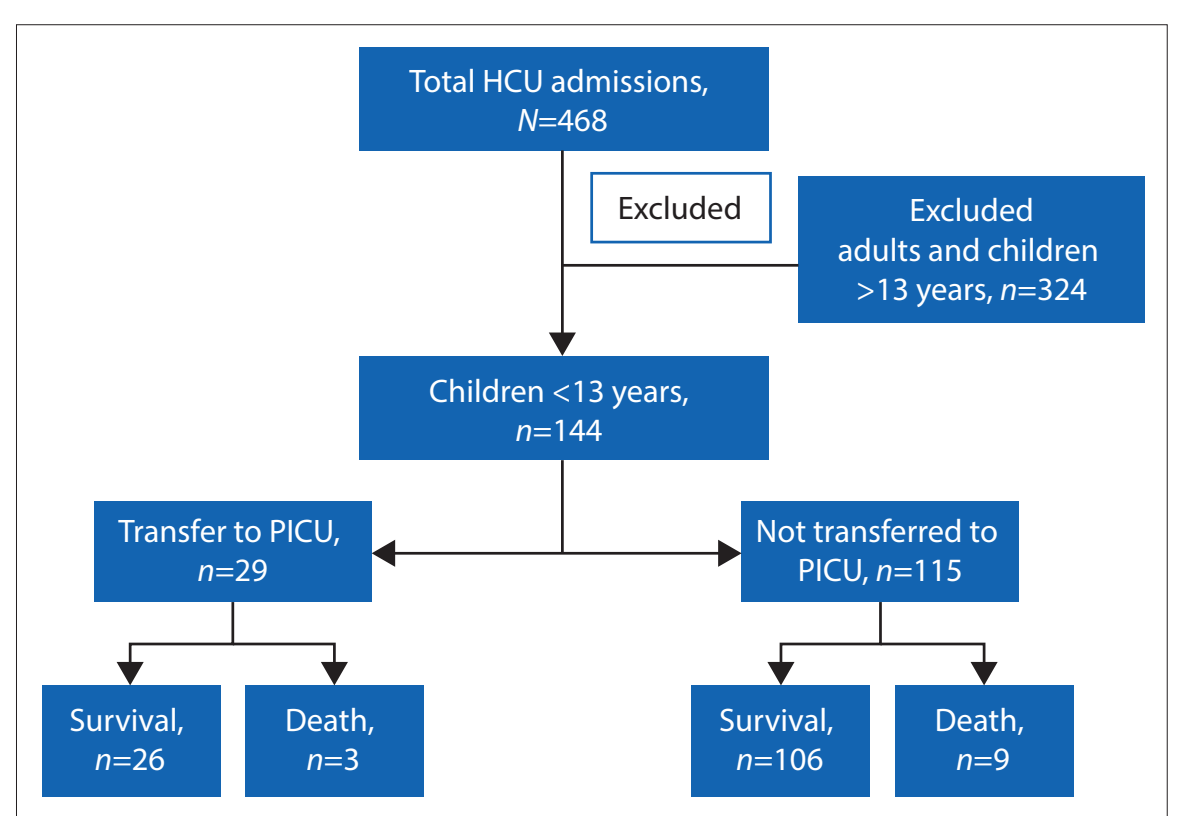

Fig. 1. Sampling strategy, including transfer data and outcomes. (HCU = high-care unit; $P I C U=$ paediatric intensive care unit.)

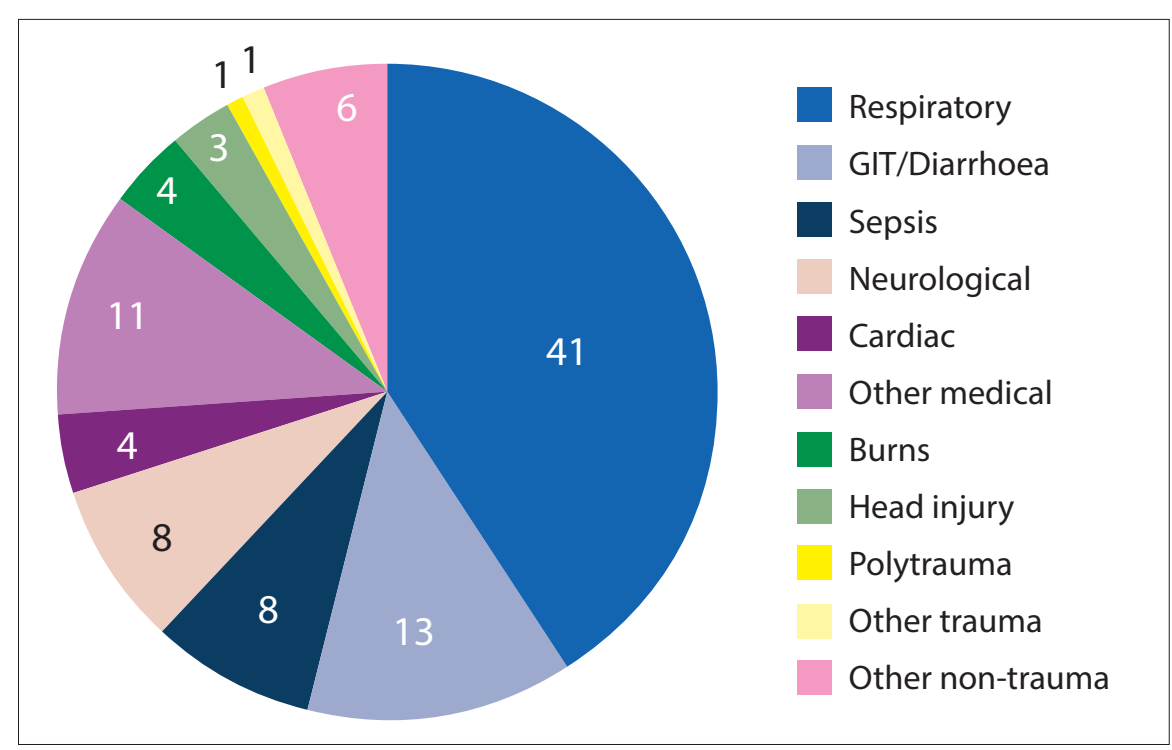

Fig. 2. Diagnostic categories represented as percentages of admissions (GIT = gastrointestinal tract.)

George Regional Hospital, during transfer and at the designated tertiary PICU.

Most of the admissions had respiratory or gastrointestinal/diarrhoeal disease (Fig. 2) (Table 5). Medical patients generally tended to be younger (median age 7 months; range 3 days -11 years; $p=0.0001$ ) than the surgical patients, of whom half were older than 5 years (range 3 months - 12 years).

Almost two-thirds $(62.71 \% ; n=37 / 58)$ of the respiratory cases had pneumonia. Other respiratory cases included seven patients with bronchiolitis $(11.86 \% ; n=7 / 58)$, two exacerbations of asthma $(3.4 \% ; n=2 / 58)$, four cases of laryngotracheobronchitis $(6.78 \% ; n=4 / 58)$, three aspiration events 


\begin{tabular}{|c|c|c|c|}
\hline Variables & $n(\%)$ & Transfer to PICU, $n(\%)$ & Mortality, $n(\%)$ \\
\hline \multicolumn{4}{|l|}{ Sex } \\
\hline Male & $74(51.39)$ & $14(9.72)$ & $5(3.47)$ \\
\hline Female & $70(48.61)$ & $15(10.42)$ & $7(4.86)$ \\
\hline \multicolumn{4}{|l|}{ Age } \\
\hline$<1$ month & $30(20.83)$ & $4(2.78)$ & $6(4.17)$ \\
\hline $1-12$ months & $50(34.72)$ & $10(6.94)$ & $2(1.39)$ \\
\hline 1 - 5 years & $34(23.61)$ & $7(4.86)$ & $2(1.39)$ \\
\hline$>5$ years & $30(20.83)$ & $8(5.56)$ & $2(1.39)$ \\
\hline \multicolumn{4}{|c|}{ Immunisations complete } \\
\hline Yes & $80(55.56)$ & $13(9.03)$ & $7(4.86)$ \\
\hline No & $15(10.42)$ & $4(2.78)$ & $2(1.39)$ \\
\hline Unknown & $49(34.03)$ & $12(8.33)$ & $3(2.08)$ \\
\hline \multicolumn{4}{|l|}{ HIV status } \\
\hline Infected & $6(4.17)$ & 0 & $1(0.69)$ \\
\hline Uninfected & $100(69.44)$ & $24(16.67)$ & $9(6.25)$ \\
\hline Unknown & $38(26.39)$ & $5(3.47)$ & $2(1.39)$ \\
\hline \multicolumn{4}{|c|}{ Weight for age $(N=134)$} \\
\hline $2 \mathrm{SD}>\mathrm{Z}>-2 \mathrm{SD}$ & $80(59.70)$ & $17(12.69)$ & $6(4.48)$ \\
\hline$-2 \mathrm{SD}>\mathrm{Z}>-3 \mathrm{SD}$ & $28(20.90)$ & $5(3.73)$ & $2(1.49)$ \\
\hline $\mathrm{Z}<-3 \mathrm{SD}$ & $22(16.42)$ & $5(3.73)$ & $3(2.24)$ \\
\hline $3 \mathrm{SD}>\mathrm{Z}>2 \mathrm{SD}$ & $2(1.49)$ & $1(0.75)$ & $1(0.75)$ \\
\hline $\mathrm{Z}>3 \mathrm{SD}$ & $2(1.49)$ & 0 & 0 \\
\hline \multicolumn{4}{|c|}{ Height for age $(N=114)$} \\
\hline $2 \mathrm{SD}>\mathrm{Z}>-2 \mathrm{SD}$ & $69(47.92)$ & $9(6.25)$ & $2(1.85)$ \\
\hline$-2 \mathrm{SD}>\mathrm{Z}>-3 \mathrm{SD}$ & $15(10.42)$ & $2(1.39)$ & 0 \\
\hline $\mathrm{Z}<-3 \mathrm{SD}$ & $24(16.67)$ & $5(3.47)$ & $1(0.93)$ \\
\hline $3 \mathrm{SD}>\mathrm{Z}>2 \mathrm{SD}$ & $3(2.08)$ & 0 & 0 \\
\hline $\mathrm{Z}>3 \mathrm{SD}$ & $3(2.08)$ & 0 & 0 \\
\hline \multicolumn{4}{|c|}{ Weight for height/BMI $(N=108)$} \\
\hline $2 \mathrm{SD}>\mathrm{Z}>-2 \mathrm{SD}$ & $81(75.00)$ & $9(8.33)$ & $2(1.85)$ \\
\hline$-2 \mathrm{SD}>\mathrm{Z}>-3 \mathrm{SD}$ & $14(12.96)$ & $4(3.70)$ & 0 \\
\hline$Z<-3 S D$ & $11(10.19)$ & $3(2.78)$ & $1(0.93)$ \\
\hline $3 \mathrm{SD}>\mathrm{Z}>2 \mathrm{SD}$ & $2(1.85)$ & 0 & 0 \\
\hline $\mathrm{Z}>3 \mathrm{SD}$ & 0 & 0 & 0 \\
\hline
\end{tabular}

Table 2. Description of admission to high-care unit and transfer to paediatric intensive care unit $(N=144)$

\begin{tabular}{|c|c|c|c|}
\hline Variables & $n(\%)$ & Deaths, $n$ & $p$-value \\
\hline \multicolumn{4}{|c|}{ After-hours admission to HCU } \\
\hline Yes & $100(69.44)$ & 10 & 0.275 \\
\hline No & $44(30.56)$ & 2 & \\
\hline \multicolumn{4}{|c|}{ Duration of stay in HCU, days } \\
\hline$<2$ & $82(56.94)$ & 8 & 0.894 \\
\hline $2-3$ & $20(13.89)$ & 2 & \\
\hline $3-5$ & $22(15.28)$ & 0 & \\
\hline$>5$ & $20(13.89)$ & 2 & \\
\hline \multicolumn{4}{|c|}{ Transfer to PICU } \\
\hline Yes & $29(20.14)$ & 3 & 0.754 \\
\hline No & $115(79.86)$ & 9 & \\
\hline \multicolumn{4}{|c|}{ Waiting time until transfer, hours $(N=29)$} \\
\hline$<24$ & $17(58.62)$ & 1 & 0.351 \\
\hline $24-48$ & $7(24.14)$ & 2 & \\
\hline$>48$ & $5(17.25)$ & 0 & \\
\hline
\end{tabular}


(5.08\%; $n=3 / 58)$, four cases of subglottic stenosis $(6.78 \% ; n=4 / 59)$ and two of severe obstructive sleep apnoea $(3.39 \% ; n=2 / 58)$. Almost a third of the cases with pneumonia $(29.73 \% ; n=11 / 37)$ also presented with a congenital cardiac lesion.

Six patients $(4.17 \% ; n=6 / 144)$ were admitted with primarily cardiac disorders, including two cases of probable myocarditis, one with cor pulmonale from obstructive sleep apnoea, two complex congenital cardiac lesions and one with mitral valve disease and heart failure.

Of the 19 cases with gastrointestinal disorders (13.19\%, $n=19 / 144)$, 18 were admitted with acute diarrhoea and shock. This was defined as recent onset of profuse loose, watery stools ( $<2$ weeks). Shock was present when a delayed capillary refilling time ( $>3$ seconds), weak pulse rate, decreased pulse volume, cool peripheries, decreased level of consciousness or decreased blood pressure was associated with diarrhoea. One patient had chronic diarrhoea ( $>2$ weeks) with cytomegalovirus disease. One patient with phenotypic features of Down syndrome was admitted with acute diarrhoea and shock (karyotype not performed).

Of the patients with neurological disease, six $(54.55 ; n=6 / 11)$ presented with status epilepticus, two $(18.2 \% ; n=2 / 11)$ with acute flaccid paralysis, two $(18.2 \% ; n=2 / 11)$ with encephalitis and one $(9.1 \% ; n=1 / 11)$ with bilateral intraventricular haemorrhage.

Table 3. Reasons for delay of more than 24 hours in transfer to paediatric intensive care unit $(n / N=12 / 29)$

\begin{tabular}{ll}
\hline Description & $n$ \\
\hline Lack of PICU bed availability & 5 \\
Patient unstable & 5 \\
Weather conditions unsuitable for air transfer & 1 \\
No reason noted & 1 \\
PICU = paediatric intensive care unit. &
\end{tabular}

Five patients $(3.47 \% ; n=5 / 144)$ had diabetic ketoacidosis and two patients $(1.39 \% ; n=2 / 144)$ were admitted with haematological disorders and bleeding. One patient $(0.69 \% ; n=1 / 144)$ had nephrotic syndrome and possible spontaneous bacterial peritonitis. Seven patients $(4.86 \% ; n=7 / 144)$ were admitted after toxin or drug ingestion. One patient $(0.69 \% ; n=1 / 144)$ had acute liver injury from an unknown cause and another $(0.69 \% ; n=1 / 144)$ presented with nonspecific symptoms and signs of headache, lethargy, fever and petechiae.

The majority $(59.09 \% ; n=13 / 22)$ of surgical admissions were trauma related. Other trauma cases included one drowning $(0.69 \%$, $n=1 / 144)$ and one crush injury $(0.69 \% ; n=1 / 144)$. The non-trauma cases included two patients with ruptured appendices $(1.39 \%$; $n=2 / 144)$, two with bowel obstruction ( $1.39 \% ; n=2 / 144)$, one with intussusception $(0.69 \%$; $n=1 / 144)$, two cases of post cleft palate repair $(1.39 \% ; n=2 / 144)$, one post adenotonsillectomy case $(0.69 \%$; $n=1 / 144)$ and one case of septic hip arthritis $(0.69 \% ; n=1 / 144)$. Mechanical ventilation was required in 14 of the surgical cases $(63.64 \% ; n=14 / 22)$ and seven cases $(31.82 \% ; n=7 / 22)$ needed inotropic support. No statistically significant difference was observed for additional support between medical and surgical cases $(p=0.611)$ nor with regard to duration of ventilatory $(p=0.181)$ or inotropic $(p=0.328)$ support.

The cumulative PIM3 value for the study population was 9.049 (95\% confidence interval (CI) 6.430 - 11.668), with minimal interobserver variability (Spearman correlation value 0.9771, $p=0.000)$. The expected number of deaths was therefore 9 out of 144 cases. The SMR was calculated as 1.326 (95\% CI 1.028 - 1.866). Patients who were transferred to the PICU had a significantly lower PIM3 score than those who continued care at the HCU $(p=0.0495)$.

\section{Discussion}

This study demonstrates that children made up close to a third of all admissions to the regional hospital HCU. Although not significantly

Table 4. Respiratory and inotropic support administered, including at the George Regional Hospital, during transport and at the paediatric intensive care unit $(N=144)$

\begin{tabular}{|c|c|c|c|c|}
\hline Type of support and parameters & $n(\%)$ & Deaths $(N=12), n$ & $p$-value & OR $(95 \% \mathrm{CI})$ \\
\hline \multicolumn{5}{|l|}{ Ventilation } \\
\hline None & $51(35.42)$ & 0 & \multirow{4}{*}{$\begin{array}{l}0.007 \text { (any } \\
\text { ventilation) }\end{array}$} & \\
\hline CPAP & $36(25.00)$ & 3 & & \\
\hline IPPV & $35(24.30)$ & 6 & & \\
\hline CPAP and IPPV & $22(15.28)$ & 3 & & \\
\hline \multicolumn{5}{|l|}{ Inotropic support } \\
\hline No & $79(54.86)$ & 5 & \multirow{2}{*}{$\begin{array}{l}0.000 \text { (any } \\
\text { inotropic support) }\end{array}$} & \\
\hline Yes & $65(45.14)$ & 7 & & \\
\hline \multicolumn{5}{|c|}{ Duration of ventilation support, days $(N=90)^{*}$} \\
\hline$<1$ & $14(15.56)$ & 4 & \multirow[t]{4}{*}{0.022} & $0.4(0.125-1.275)$ \\
\hline $1-3$ & $23(25.56)$ & 5 & & $0.278(0.103-0.748)$ \\
\hline $3-6$ & $21(23.32)$ & 1 & & $0.05(0.007-0.373)$ \\
\hline$>6$ & $32(35.56)$ & 2 & & $0.067(0.016-0.279)$ \\
\hline \multicolumn{5}{|c|}{ Duration of inotropic support, days $(N=62)^{\dagger}$} \\
\hline$<1$ & $9(14.52)$ & 5 & \multirow[t]{4}{*}{0.013} & $1.25(0.336-4.655)$ \\
\hline $1-3$ & $34(54.84)$ & 5 & & $0.172(0.067-0.445)$ \\
\hline $3-6$ & $10(16.12$ & 2 & & $0.053(1.177)$ \\
\hline$>6$ & $9(14.52)$ & 0 & & 0 \\
\hline
\end{tabular}


Table 5. Diagnostic categories of patients admitted to the HCU $(N=144)$, followed by transfer to the PICU or death

\begin{tabular}{|c|c|c|c|c|c|}
\hline Primary diagnosis & $\begin{array}{l}\text { Frequency, } \\
n(\%)\end{array}$ & $\begin{array}{l}\text { Transfers }(N=29), \\
n(\%)\end{array}$ & $\begin{array}{l}\text { Deaths }(N=12), \\
n^{\star}\end{array}$ & $\begin{array}{l}\text { OR of transfer }(95 \% \\
\mathrm{CI})\end{array}$ & $\begin{array}{l}\text { OR of death }(95 \% \\
\mathrm{CI})\end{array}$ \\
\hline Medical & $122(84.72)$ & $21(72.41)$ & $12(3)$ & $0.208(0.130-0.333)$ & $0.109(0.060-0.198)$ \\
\hline Respiratory & $58(40.28)$ & $14(48.28)$ & $3(2)$ & $0.318(0.174-0.581)$ & $0.055(0.017-0.174)$ \\
\hline GIT/diarrhoea & $19(13.19)$ & $1(3.45)$ & $3(1)$ & 0 & $0.188(0.055-0.643)$ \\
\hline Sepsis & $11(7.64)$ & $1(3.45)$ & 6 & $0.1(0.013-0.781)$ & $1.2(0.366-3.932)$ \\
\hline Neurological & $11(7.64)$ & $3(10.34)$ & & $0.375(0.099-1.414)$ & \\
\hline Cardiac & $6(4.17)$ & $2(6.90)$ & & $0.5(0.092-2.730)$ & \\
\hline Other & $17(11.11)$ & 0 & & $0.063(0.008-0.471)$ & \\
\hline Toxin/drug & $7(4.86)$ & & & & \\
\hline DKA & $5(3.47)$ & & & & \\
\hline Haematological & $2(1.39)$ & & & & \\
\hline Acute liver injury & $1(0.69)$ & & & & \\
\hline Nephrotic syndrome & $1(0.69)$ & & & & \\
\hline Not specified & $1(0.69)$ & & & & \\
\hline Surgical & $22(15.28)$ & $8(27.59)$ & 0 & $0.571(0.240-1.362)$ & 0 \\
\hline Burns & $6(4.17)$ & $4(13.80)$ & & $2.0(0.366-10.920)$ & \\
\hline Head injury & $4(2.78)$ & $2(6.90)$ & & $1.0(0.141-7.100)$ & \\
\hline Polytrauma & $1(0.69)$ & $1(3.45)$ & & & \\
\hline Other trauma & $2(1.39)$ & 0 & & 0 & \\
\hline Drowning & $1(0.69)$ & & & & \\
\hline Crush injury & $1(0.69)$ & & & & \\
\hline Other non-trauma & $9(6.25)$ & $1(3.45)$ & & $0.125(0.016-1.000)$ & \\
\hline Appendicitis & $2(1.39)$ & & & & \\
\hline Bowel obstruction & $2(1.39)$ & $1(3.45)$ & & $0.125(0.016-1.000)$ & \\
\hline Intussusception & $1(0.69)$ & & & & \\
\hline Cleft palate repair & $2(1.39)$ & & & & \\
\hline Adenotonsillectomy & $1(0.69)$ & & & & \\
\hline Septic hip arthritis & $1(0.69)$ & & & & \\
\hline
\end{tabular}

associated with death, it is concerning that more than a third of the children in this study were underweight and stunted and almost a quarter were wasted. These statistics are in keeping with trends observed in a recent meta-analysis of anthropometric data among children in SA, although the trend towards increased overnutrition was not observed. ${ }^{[27]}$ Underweight children have a higher risk of poor critical care outcomes. ${ }^{[28]}$

The overall low mortality reflects a good outcome. ${ }^{[16,25]}$ The number of deaths occurring in the first few days of admission reflects the severity of critical illness in the initial period. ${ }^{[28]}$ The observed trend of death occurring in younger children is in keeping with other studies. ${ }^{[29]}$ HIV infection did not have a significant effect on mortality, which could reflect better outcomes due to antiretroviral therapy. ${ }^{[30]}$ It is concerning to note the large proportion of undocumented HIV statuses, indicating the need for improved documentation and vigilance in testing.

Although after-hours admission did not significantly affect outcome, it does place more strain on the on-call staff and may affect morbidity ${ }^{[31]}$ Almost a third $(29.17 \% ; n=42 / 144)$ of the patients were admitted for a prolonged period ( $>72$ hours), adding burden on local resource use. This is comparable to findings from a recent study at the PICU of the Red Cross War Memorial Children's Hospital, Cape Town (the tertiary referral hospital in our study), which found that during a 1-year period, $50 \%$ of all admissions were admitted for three days or longer. ${ }^{[32]}$
George Regional Hospital serves not only the third largest subpopulation in the province (Western Cape) but also the poorest (Central Karoo) and third wealthiest (Eden) communities, based on gross domestic product per capita. ${ }^{[33]}$ Together, the districts cover almost $50 \%$ of the total geographical area of the Western Cape. ${ }^{[34]}$ The distance to the nearest tertiary PICU is $427 \mathrm{~km}$, which is substantially further than the distance from other regional hospitals such as Worcester $(96 \mathrm{~km})$ and Paarl Hospital $(48 \mathrm{~km})$ and therefore the air ambulance service is a necessity. The service is efficient and safe with generally short waiting times and no mortalities during transfer. ${ }^{[35]}$ The service is delivered by a private company (EMS 24/7) and therefore the cost must be considered. ${ }^{[35]}$ Owing to patient instability, some transfers were not possible. The median PICU stay of 6 days suggests that most referrals were appropriate. The admission criteria at the designated tertiary PICU are based on international guidelines and incorporate local policy to ensure optimal use of scarce ICU services while keeping the best interests of the patient and equitable access in mind. Avoidance of prolonged stays in referred cases indicates good use of critical-care resources. ${ }^{[24,25]}$

A relatively small proportion of the admissions $(20.14 \%$; $n=29 / 144)$ required transfer to the PICU. The regional hospital team were therefore responsible for the definitive management of the majority of critically ill children. This requires specific training, skills and equipment. ${ }^{[36]}$ 
CPAP and inotropic support can be provided in the general ward at George Regional Hospital. Some of the children were therefore already receiving ventilatory or inotropic support prior to and even after discharge or transfer from the HCU. This requires added expertise and vigilance from ward staff, which is not necessarily available.

As expected, pneumonia and diarrhoea made up a large proportion of the diagnoses and introduced an increased risk of death. These conditions have also been shown to be the leading causes of death elsewhere in the Western Cape. ${ }^{[37]}$ Confirmed sepsis is also a significant cause of death in critically ill children. ${ }^{[28]}$

The high proportion of trauma or injury-related surgical admissions is concerning. More than $60 \%$ of deaths in children older than 5 years in the Western Cape are related to trauma or injury. ${ }^{[38]}$ This number also seems to be increasing at national level. ${ }^{[39]}$

The relatively higher number of deaths observed in this study, compared with one-year statistics from Worcester Hospital in $2008-2009(n=12 / 185)$, may be explained by multiple factors. ${ }^{[16]}$ In that study, transferred patients were not assessed further for survival at the tertiary centre. ${ }^{[16]}$ The relative ease of transfer to the tertiary PICU due to closer proximity and access by road may have contributed to a lower mortality rate. ${ }^{[40,41]}$

To our knowledge, this is the first study to apply the PIM3 score to a critical-care unit at regional level (i.e. George Regional Hospital HCU). This score has not been validated at this level and should be interpreted with caution. A lower PIM3 score for the transferred cases could explain the low mortality rate at the PICU. ${ }^{[22]}$ The worse-than-expected SMR could be due to many factors, including the lack of paediatric critical care training, a study population with inherently poorer health due to poverty and malnutrition, and limited on-site availability of senior doctors after hours. ${ }^{[23,42,43]}$ In light of this observation, more regionalised critical care support, such as technology-enabled remote care (telemedicine) from the PICU or specialist outreach programmes, could be considered. ${ }^{[44,45]}$

\section{Study limitations}

Retrospective data collection, coupled with documentation discrepancies regarding times of interventions, admissions and transfers, was a limitation of the study. In addition, the study period was fairly short and a small population size was used. HIV exposure was also not documented. The neonatal area functions independently, which makes it difficult to compare this study with others in the SA setting. ${ }^{[16]}$ Further study is needed to assess neonatal critical care in the region.

The application of a scoring system that has not been validated in this setting limits the value of interpreting the SMR. ${ }^{[22]}$ Future studies could assess morbidity and long-term effects of critical disease and contribute to validating other mortality scoring systems at regional level.

\section{Conclusion}

Critically ill children made up a large portion of the admissions to the George Regional Hospital HCU. Most of the children required medical interventions such as inotropes and respiratory support. Only a fifth of the children were referred to the tertiary PICU, indicating a need for regional hospital staff to be competent in managing critically ill children. General paediatricians and surgeons working in regional hospitals should be confident in treating very ill children and must ensure that junior doctors are trained in working in this environment. Special training of nurses and adequate availability of equipment are necessary to ensure good outcomes.
Most of the children in this study were successfully discharged. This reflects the good quality of care at regional level, during air transfer and at the tertiary PICU. Prompt stabilisation and care, together with appropriate transfer to the tertiary facility, are necessary to avoid mortality; however, owing to limited bed availability at the tertiary unit, weather limitations and patient instability, transfer is not always feasible.

More studies are needed to assess the care of critically ill children at regional level in SA. Mortality predictors may be relevant in regional hospital settings, but more studies are needed to validate these models. Such predictors could be valuable in comparing services across hospitals and assisting in health system planning.

Declaration. This manuscript was submitted in partial fulfilment of the requirements for the MMed degree at the University of Cape Town.

Acknowledgements. The authors acknowledge the contributions of all team members at the George Regional Hospital and Red Cross War Memorial Children's Hospital PICU involved in the care of these patients. We also acknowledge and thank the EMS 24/7 team involved in patient transfers. Special thanks are extended to Ms T Dywili for assisting with translating the informative poster into isiXhosa.

Author contributions. RV was responsible for research conceptualisation, data collection and analysis, and manuscript development. WJB was the local co-supervisor and was involved in research conceptualisation and data collection. SS was the main supervisor and contributed to research conceptualisation, data analysis and manuscript development.

Funding. A University of Cape Town MMed research grant was received for this research.

Conflicts of interest. None.

1. Statistics South Africa. 2018. Mortality and causes of death in South Africa, 2016: Findings from death notification. Pretoria: SA, 2018. https://www.statssa. gov.za/publications/P03093/P030932016.pdf

2. Murthy S, Adhikari NK. Global health care of the critically ill in low-resource settings. Ann Am Thorac Soc 2013;10(5):509-513. https://doi.org/10.1513/ AnnalsATS.201307-246OT

3. American College of Emergency Physicians. Coding and reimbursement pearls: Critical care. https://www.acep.org/administration/reimbursement/ coding-and-reimbursement-pearls/\#CriticalCare (accessed 15 November 2019).

4. Bettings P, Diedericks J, Fourie P, et al. SASA practice guidelines 2012. S Afr J Anaesth Analg 2013;19(1):s33-s34. https://hdl.handle.net/10520/EJC132092

5. Bhagwanjee S, Scribante J. National audit of critical care resources in South Africa - unit and bed distribution. S Afr Med J 2007;97(12 Pt 3):1311-1314.

6. Prin $M$, Wunsch H. International comparisons of intensive care: Informing outcomes and improving standards. Curr Opin Crit Care 2012;18(6):700-706. https://doi.org/10.1097/MCC.0b013e32835914d5

7. Bamford LJ, McKerrow NH, Barron P, Aung Y. Child mortality in South Africa: Fewer deaths, but better data are needed. S Afr Med J 2018;108(3a): s25-s32. https://doi.org/10.7196/SAMJ.2017.v108i3b.12779

8. Western Cape Government Provincial Treasury. Regional development profile: Karoo district. https://www.westerncape.gov.za/assets/departments/ treasury/dc05_central_karoo_2012_sep_lg_profile_nov_2012.pdf (accessed 10 November 2019).

9. Western Cape Government Provincial Treasury. Regional development profile: Eden district. https://www.westerncape.gov.za/assets/departments/ treasury/Documents/Socio-economic-profiles/eden_regional_development_ profile_2013_ella_6_des_2013_nb.pdf (accessed 16 November 2019).

10. United Nations Statistics Division. SDG Indicators: Official list of SDG indicators. 2016. https://unstats.un.org/sdgs/indicators/Global\%20Indicator\%20 Framework\%20after\%202020\%20review_Eng.pdf (accessed 10 November 2019).

11. Paediatric Intensive Care Society. Standards for the care of critically ill children 2010. London: Paediatric Intensive Care Society, 2010. http://picsociety.uk/wpcontent/uploads/2015/10/PICS_standards_2010.pdf.

12. Pollack MM, Alexander SR, Clarke N, Ruttimann UE, Tesselaar HM, Bachulis AC. Improved outcomes from tertiary center pediatric intensive care: A statewide comparison of tertiary and nontertiary care facilities. Crit Care Med 1991;19(2):150-159. https://doi.org/10.1097/00003246-199102000-00007 
13. Pearson G, Shann F, Barry P, et al. Should paediatric intensive care be centralised? Trent versus Victoria. Lancet 1997;349:1213-1217. https://doi. org/10.1016/S0140-6736(96)12396-5

14. Campos-Miño S, Sasbón JS, Von Dessauer B. [Pediatric intensive care in Latin America]. Med Intensiva 2012;36(1):3-10. [https://doi.org/10.1016/j. medin.2011.07.004]

15. Hatherill M, Waggie Z, Reynolds L, Argent A. Transport of critically ill children in a resource-limited setting. Intensive Care Med 2003;29(9):1547-1554. https://doi.org/10.1007/s00134-003-1888-7

16. Kruger I, Gie R, Harvey J, Kruger M. Outcome of children admitted to a general high-care unit in a regional hospital in the Western Cape, South Africa. S Afr J Child Health 2016;10(3):156-160. https://doi.org/10.7196/SAJCH.2016. v10i3.981

17. Shann F, Pearson G, Slater A, Wilkinson K. Paediatric index of mortality (PIM): A mortality prediction model for children in intensive care. Intensive Care Med 1997;23:201-207. https://doi.org/10.1007/s001340050317

18. Pollack MM, Ruttimann UE, Getson PR. Pediatric risk of mortality (PRISM) score. Crit Care Med 1988;16(11):1110-1116. https://doi.org/10.1097/00003246198811000-00006

19. Ciofi degli Atti ML, Cuttini M, Ravà L, et al. Performance of the pediatric index of mortality 2 (PIM-2) in cardiac and mixed intensive care units in a tertiary children's referral hospital in Italy. BMC Pediatr 2013;13:100. https:// doi.org/10.1186/1471-2431-13-100

20. Gandhi J, Sangareddi S, Varadarajan P, Suresh S. Pediatric index of mortality 2 score as an outcome predictor in pediatric intensive care unit in India. Indian J Crit Care Med 2013;17(5):288-291. https://doi.org/10.4103/0972-5229.120320

21. Solomon LJ, Morrow BM, Argent AC. Paediatric Index of Mortality scores: An evaluation of function in the paediatric intensive care unit of the Red Cross War Memorial Children's Hospital. S Afr J Crit Care 2014;30(1): 8-13. https:// doi.org/10.7196/SAJCC.166

22. Straney L, Clements A, Parslow RC, et al. Paediatric Index of Mortality 3: An updated model for predicting mortality in pediatric intensive care. Pediatric Crit Care Med 2013;14(7):673-681. https://doi.org/10.1097/PCC.0b013e31829760cf

23. Hendricks CL, McKerrow NH, Hendricks RJ. Factors present on admission associated with increased mortality in children admitted to a paediatric intensive care unit (PICU). S Afr J Child Health 2016;10(1):57-62. https://doi. org/10.7196/SAJCH.2016.v10i1.1048

24. American Academy of Pediatrics. Committee on Hospital Care and Section of Critical Care. Society of Critical Care Medicine. Pediatric Section Admission Criteria Task Force. Guidelines for developing admission and discharge policies for the pediatric intensive care unit. Pediatrics 1999;103(4 Pt 1):840-842.

25. Argent AC, Ahrens J, Morrow BM, et al. Pediatric intensive care in South Africa: An account of making optimum use of limited resources at the Red Cross War Memorial Children's Hospital. Pediatr Crit Care Med 2014;15(1):714. https://doi.org/10.1097/PCC.0000000000000029

26. World Health Organization. WHO Child Growth Standards: Length/Heightfor-Age, Weight-for-Age, Weight-for-Length, Weight-for-Height and Body Mass Index-for-Age: Methods and Development. Geneva: WHO, 2006.

27. Monyeki MA, Awotidebe A, Strydom GL, De Ridder JH, Mamabolo RL, Kemper HCG. The challenges of underweight and overweight South African children: Are we winning or losing the battle? A systematic review. Int J Environ Res Public Health 2015;12(2):1156-1173. https://doi.org/10.3390/ijerph120201156

28. Weiss SL, Balamuth F, Hensley J, et al. The epidemiology of hospital death following pediatric severe sepsis: When, why, and how children with sepsis die. Pediatr Crit Care Med 2017;18(9):823-830. https://doi.org/10.1097/ PCC. 0000000000001222

29. Basnet S, Adhikari N, Koirala J. Challenges in setting up pediatric and neonatal intensive care units in a resource-limited country. Pediatrics 2011;128(4):e986-e992. https://doi.org/10.1542/peds.2010-3657
30. Cowburn C, Hatherill M, Eley B, et al. Short-term mortality and implementation of antiretroviral treatment for critically ill HIV-infected children in a developing country. Arch Dis Child 2007;92(3):234-241. https:// doi.org/10.1136/adc.2005.074856

31. Typpo KV, Hossein Tcharmtchi M, Thomas EJ, Kelly PA, Castillo LD, Singh $\mathrm{H}$. Impact of resident duty hour limits on safety in the ICU: A national survey of pediatric and neonatal intensivists. Pediatr Crit Care Med 2013;13(5):578582. https://doi.org/10.1097/PCC.0b013e318241785c

32. Nupen TL, Argent AC, Morrow BM. Characteristics and outcome of long-stay patients in a paediatric intensive care unit in Cape Town, South Africa. S Afr Med J 2017;107(1):70-75. https://doi.org/10.7196/samj.2017.v107i1.11279

33. Western Cape Government. Socio-Economic Profile. Eden District Municipality 2017. https://www.westerncape.gov.za/assets/departments/ treasury/Documents/Socio-economic-profiles/2017/dc03_eden_ district_2017_socio-economic_profile_sep-lg_21_january_2018.pdf (accessed 12 November 2019).

34. Yes Media. Municipalities of South Africa. Western Cape: Garden Route District Municipality, Central Karoo District Municipality. https:// municipalities.co.za/provinces/view/9/western-cape (accessed 12 November 2019).

35. Van Hoving DJ, Smith WP, Wallis LA. Comparison of mean on-scene times: Road versus air transportation of critically ill patients in the Western Cape of South Africa. Emerg Med J 2008;25:136-139. https://doi.org/10.1136/ emj.2007.051540

36. Argent AC. From home to definitive care for critically ill children: Barriers and solutions. Curr Treat Options Pediatr 2015;1(2):119-131. https://doi. org/10.1007/s40746-015-0018-4

37. Reid AE, Hendricks MK, Groenewald P, Bradshaw D. Where do children die and what are the causes? Under-5 deaths in the Metro West geographical service area of the Western Cape, South Africa, 2011. S Afr Med J 2016;106(4):359-364. https://doi.org/10.7196/SAMJ.2016.v106i4.10521

38. Morden E, Groenewald P, Zinyakatira N, et al. Western Cape Mortality Profile 2013. Cape Town: South African Medical Research Council, 2016.

39. Statistics South Africa. Community survey 2016, Statistical release P0301. Pretoria: SSA, 2016. https://cs2016.statssa.gov.za/wp-content/ uploads/2016/07/NT-30-06-2016-RELEASE-for-CS-2016-_Statisticalreleas_1-July-2016.pdf

40. Kulshrestha A, Singh J. Inter-hospital and intra-hospital patient transfer: Recent concepts. Indian J Anaesth 2016;60(7):451-457. https://doi. org/10.4103\%2F0019-5049.186012

41. Singh JM, MacDonald RD, Bronskill SE, Schull MJ. Incidence and predictors of critical events during urgent air-medical transport. CMAJ 2009;181(9):579584. https://doi.org/10.1503/cmaj.080886

42. Slusher TM, Kiragu AW, Day LT, et al. Pediatric critical care in resourcelimited settings - overview and lessons learned. Front Pediatr 2018;6:49. https://doi.org/10.3389/fped.2018.00049

43. Masud F, Lam TYC, Sahar F. Is 24/7 in-house intensivist staffing necessary in the intensive care unit? Methodist Debakey Cardiovasc J 2018;14(2):134-140. https://doi.org/10.14797/mdcj-14-2-134

44. Caldwell RI, Grant M, Gaede B, Aldous C. Enabling factors for specialist outreach in western KwaZulu-Natal. Afr J Prim Health Care Fam Med 2018;10(1):1690. https://doi.org/10.4102/phcfm.v10i1.1690

45. Rosenfield BA, Dorman T, Breslow MJ, et al. Intensive care unit telemedicine: Alternate paradigm for providing continuouys intensivist care. Crit Care Med 2000;28(12):3925-3931. https://doi.org/10.1097/00003246-200012000-00034

Accepted 26 May 2020 